\title{
Letters
}

Website: bmj.com

Email: letters@bmj.com

\section{Not again!}

Designing safer medical devices requires financial and political support

EDITOR-Berwick emphasises the need to redesign medical devices to help avoid errors. ${ }^{1}$ In the European Union a task group from the European Standards Organisation (CEN) reported on ways to reduce the incidents of accidental misconnection of lines to patients. ${ }^{2}$ It identified a need to differentiate between connectors used in lines and syringes for enteral feeding, vascular access, and administering and sampling gases in the respiratory system, including a risk analysis of the results of misconnection.

The report was not welcomed by EUCOMED, which represents several European medical device manufacturers, because its proposals create more hazards for users and increase costs in a highly competitive sector of the medical device industry with high volume, low cost products. The Japanese government changed the design of connectors on syringes and enteral feed systems in less than a year because of an associated death, but none of the standards bodies in the European Union has so far volunteered to develop new standards for connector systems, as recommended by the task

\section{Advice to authors}

We prefer to receive all responses electronically, sent either directly to our website or to the editorial office as email or on a disk. Processing your letter will be delayed unless it arrives in an electronic form.

We are now posting all direct submissions to our website within 24 hours of receipt and our intention is to post all other electronic submissions there as well. All responses will be eligible for publication in the paper journal.

Responses should be under 400 words and relate to articles published in the preceding month. They should include $\leqslant 5$ references, in the Vancouver style, including one to the BMJ article to which they relate. We welcome illustrations.

Please supply each author's current appointment and full address, and a phone or fax number or email address for the corresponding author. We ask authors to declare any competing interest. Please send a stamped addressed envelope if you would like to know whether your letter has been accepted or rejected.

Letters will be edited and may be shortened.

bmj.com

letters@bmj.com
See pp 501, 517, 562, 563

group. Central funding from the European Commission has been sought, but the work is effectively now on hold.

Many non-interchangeable keyed connectors are manufactured, mostly for specialised applications. Those that are not patented are freely available and could be fitted on to hypodermic syringes and lines, allowing differentiation of line or syringe by function-for example, respiratory, vascular, enteral, or neuraxial. A separate key for intrathecal needle and syringes is possible and would require the drugs to be supplied by the pharmacist in a specialised syringe. At least one connector system incorporates an anti-tamper lock, preventing unintended disconnection. Differentiation of connector is one prompt to increase safety, differentiation by size and shape of the drug container is another. Thus intravenous drug infusions should always be supplied with an intravenous giving set pre-attached, and intrathecal drugs with a spinal needle. However unless all access points are sealed off, drugs in an intravenous bag could be accessed by even a specialised intrathecal needle and syringe.

Currently, medical hypodermic syringes have only one permitted type of connector in two types. ${ }^{34}$ Since medical hypodermic syringes and lines are ubiquitous, the task of developing a global standard for a series of non-interchangeable connector systems for syringes and small bore tubing is daunting. Not having the correct type of syringe available in an emergency would create its own hazards. Clearly, any new designs would need to be widely tested, a task meriting a multidisciplinary approach, with support from technical, psychological, and risk analysis experts. The Department of Health has promoted the reduction of accidents ${ }^{5}$ and could take the lead here. Financial and political support, from both the medical profession and government, is urgently needed.

Philip J Bickford Smith consultant anaesthetist Anaesthetic Department, Bradford Hospitals NHS Trust, West Yorkshire BD9 6RJ bickford.smith@bradfordhospitals.nhs.uk

PJBS is the clinical expert from the United Kingdom on the CEN Forum Task Group, "Luer Connectors."

1 Berwick DM. Not again! BMJ 200 1;322:247-8. (3 February.) 2 CEN Forum Task Group, "Luer Fittings" Luer comnectorsreport to CEN.London: British Standards Institution, 2000. (PD CR 13825:2000)

3 British Standards Institution. Conical fittings with 6\% (Luer) taper for syringes, needles and certain other medical equipment.
Part 1. General requirements. London: BSI, 1994. (BS EN 20594-1:1994.)

4 British Standards Institution. Comical fittings with 6\% (Luer) taper for syringes, needles and certain other medical equipmentlock fittings. London: BSI, 1997. (BS EN 1707:1997.) 5 Department of Health. An organisation with a memory; report of the expert group on learning from adverse events in the NHS chaired by the chief medical officer. London: Stationery Office,

Erroneous intrathecal injection results from a problem with protocols

EDITOR-The erroneous intrathecal administration of vincristine to 13 patients (many of them children) in 15 years is not just a problem arising from inadequate time, training, and supervision of medical staff; neither can it be confidently prevented by modifying the equipment used. ${ }^{1}$ Though I have not had access to the various investigations, I am confident that most of the vincristine given had been labelled correctly and been prescribed for intravenous use in the patients who received it intrathecally.

The accidents all occurred for the simple reason that the national protocols for treatment of childhood acute lymphoblastic leukaemia and the various derived regimens for adult leukaemia and lymphoma require that intrathecal methotrexate and intravenous vincristine be given on the same day. This is particularly convenient for patients and their families and carers, but the resulting 10 deaths and three cases of paralysis ought to prompt a review by the bodies issuing the protocols (the Medical Research Council and others).

I know of no pharmacological reason why these two agents have to be given together, whether they are being given to induce remission or as maintenance treatment. The repeated disasters, despite the problem being well recognised by all those (senior and otherwise) involved in intrathecal treatment, surely point to the need to design the problem out of the system: give the intrathecal drugs on a separate visit to the intravenous ones. Local protocols specifying the use of the agents in separate rooms are not failsafe and not necessarily applicable or enforceable in every institution.

J R C Seale consultant haematologist Ysbyty Gwynedd, Bangor LL57 2PW jim.seale@nww-tr.wales.nhs.uk

1 Berwick DM. Not again! BMJ 2001;322:247-8. (3 February.)

\section{National guidelines are urgently needed}

EDITOR-Berwick rightly points out that mechanisms are needed to prevent tragedies such as the erroneous intrathecal injection of vincristine from happening. ${ }^{1}$ With the changes in cancer management after the Calman-Hine report, this issue 
needs to be urgently looked at and nationally agreed guidance issued.

At Sidcup we have been consciously aware of such errors and have for many years introduced practical steps to prevent this error from happening. The central chemotherapy manufacturing unit labels intrathecal treatments "for intrathecal use only" and vincristine injections "fatal if given intrathecally." The drugs are delivered in separate envelopes that are clearly marked for intrathecal or intravenous use. We separate the intravenous from the intrathecal treatment in that specialist chemotherapy nurses give the intravenous, and haematology doctors the intrathecal treatments. Intrathecal follows intravenous treatment, so vincristine is given first. Most importantly, no junior doctor is allowed to give intrathecal treatment without one of the haematology or oncology consultants supervising the procedure. The drugs are collected from the pharmacy by the specialist chemotherapy nurses and handed to the consultant or to juniors in the consultant's presence. The consultant checks the injections with the administering doctor and the electronic prescription chart is signed by both.

The problem arises not because of negligence but from lack of experience and lack of seniority. By introducing such steps we not only protect patients but raise awareness and highlight to junior doctors the fatal risk that comes from the simple switching of syringes.

Saad M B Rassam consultant in haematology and oncology

Queen Mary's Sidcup NHS Trust, Sidcup, Kent DA14 6LT

1 Berwick DM. Not again! BMJ 2001;322:247-8. (3 February.)

Only ocular treatments should be packaged like eye drops ...

EDITOR-Just as I was penning a letter about how medical errors are portrayed in the media, Berwick has said it all. ${ }^{1}$ My letter was not about a case reported in the Daily Mail, however, but about a case reported in the $B M J$.

I stared in disbelief at the picture in Minerva on 20 January 2001. ${ }^{2}$ Why would a medical company be allowed to produce a bottle of stoma deodorant that so closely matched a bottle of eye drops? I expected the authors to point this out and perhaps suggest that the Medicines Control Agency have a system for controlling the packaging of products like these. The agency has, for example, made strides in the packaging of paracetamol to reduce suicide rates. ${ }^{13}$ Instead, the authors wrote (and the $B M$ J published), "Great care must be taken when patients need ocular treatments in addition to other treatments contained in dropper bottles"-as if the staff on the ward somehow did not try to take great care. Even Berwick returns his videos to the wrong store: he should take more care and be less human.

Once again healthcare workers are being exhorted to avoid an accident waiting to happen. Furthermore, such an accident is likely to happen again-on wards, in homes (where patients with poor sight using eye drops might have problems)-until someone says that only ocular treatments should ever be put in packages that look like eye droppers.

Tim Wilson general practitioner

Mill Stream Surgery, Benson, Oxfordshire

OX10 6RL

twilson@rcgp.org.uk

1 Berwick DM. Not again! BMJ 2001;322:247-8. (3 February.) 2 Wheeler J, Shah P. Minerva picture. BMJ 2001;322:182. (20 January.)

3 Robinson D, Smith AMJ, Johnston GD. Severity of overdose after restriction of paracetamol availability: retrospective study. BMJ 2000;321:926-7. (14 October.)

\section{... and packaging of lignocaine must be changed}

EdiToR-Further to Berwick's editorial on the erroneous intrathecal injection of vincristine $^{1}$ and the picture in Minerva in the same issue on the packaging of lignocaine, ${ }^{2}$ we report a pertinent incident.

In 1994 our risk management department was made aware that the container and boxes containing $0.9 \%$ sodium chloride (normal saline) and 1\% lignocaine were almost identical and that these solutions were being used side by side in the radiology department. The potential for a serious incident of mistakenly administering lignocaine as a flush was identified. No action was taken.

In 1999 a child was administered lignocaine as a flush during an interventional procedure. The child required urgen medical attention but did not develop long term adverse effects. The incident was again reported to risk management, but no further action was taken to reduce the risk of recurrence. In April 2000 the danger of giving lignocaine for normal saline was again high-

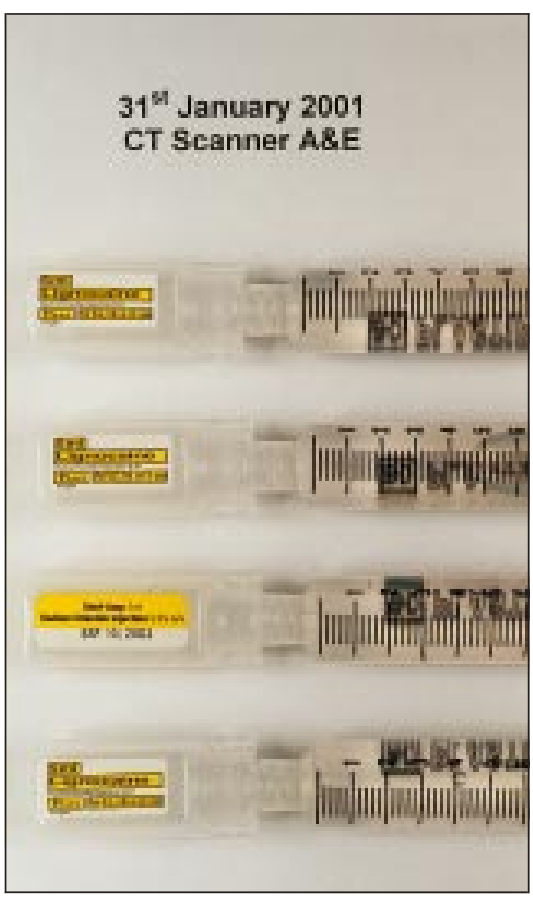

Three of four flushes were $1 \%$ lignocaine instead of normal saline on 31 January 2001 lighted at a risk management meeting; no action was taken.

On 31 January 2001 four flushes were drawn up before computed tomography (figure). Three of the four flushes were 1\% lignocaine. This was noted before injection and a near miss has been recorded and reported to risk management.

With the increasing cost of payments made by the NHS for medical negligence it is time to change the packaging of lignocaine

Anmol Malhotra radiology registrar

Mathew Matson radiology consultan

Otto Chan radiology consultant

Department of Diagnostic Imaging (Radiology),

Royal Hospitals NHS Trust, London E1 1BB

1 Berwick DM. Not again! BMJ 2001;322:247-8. (3 February.) 2 Dawes R, Vanner R. Minerva picture. BMJ 2001;322:308. (3 February.)

**Plus ça change. Dr R E Ferner of the West Midlands Centre for Adverse Drug Reaction Reporting, City Hospital NHS Trust, Birmingham $\mathrm{B} 18 \mathrm{QH}$, has reminded us that he highlighted the problem of misleading drug packaging over five years ago (BMJ 1995;311:514). He showed how labels for lignocaine and normal saline were identical apart from the lettering and suggested that diversity could mean the difference between life and death

\section{Patients must be properly informed to} agree to or decline treatment

EDITOR-Obviously errors will always occur in health care. ${ }^{1}$ Unfortunately, the medical profession has traditionally kept quiet about this sad fact of life-and death.

Doctors have considered it inappropriate to tell patients that mistakes, let alone their consequences, can all too easily occur during the course of a procedure. Therefore, patients have not had the requisite information on which to make fully informed decisions.

The motives for this secrecy have doubtless been honourable. But the desire to spare patients the additional trauma of being reminded that we are all fallible can easily slide into the suppression of crucial information about the risks associated with an intervention.

Giving patients all the information necessary to agree to or decline treatment, without generating numerous refusals, is the challenge implicit in a meaningful doctorpatient partnership.

Roger M Goss director

Patient Concern, PO Box 23732, London SW5 9FY rogerconcern@hotmail.com

1 Berwick DM. Not again! BMJ 2001;322:247-8. (3 February.)

\section{Data protection and patients' consent}

\section{Informed consent should be sought before data are used by registries}

EDIToR-The news story on the possibility that cancer registries might collapse as a result of new guidance on patient confidentiality issued by the General Medical Council 
highlighted the difficulties faced by doctors who must deal with increasing bureaucracy. ${ }^{1}$ In conjunction with a multidisciplinary team from different parts of the United Kingdom I was involved in establishing a prospective register of pregnant women with epilepsy. Pregnancy in women with epilepsy is associated with an increased risk of fetal malformation.

As with cancer, there are variations in the routine treatment of epilepsy in pregnancy. It would be considered unethical to carry out a clinical trial of treatment, but because many pregnancies occur in women already taking a variety of anti-epileptic drugs (for many of which no reliable data on teratogenicity in humans exists) valuable information could become available if only it was collated. It was on this premise that the UK Epilepsy and Pregnancy Register was established.

From the outset we identified the need for confidentiality, and all patients included in the register give informed consent. Few patients have refused or withdrawn consent, and indeed most are delighted that some research is being carried out on this subject. Although case ascertainment would probably be higher if informed consent was not necessary, this is an inevitable trade off made to maintain patients' trust.

A further difficulty faced by registries is that of formal ethical approval. Approval for our register was obtained from a multicentre research ethics committee, but this did not obviate the need to apply to over 200 local research ethics committees. Many of the local committees had idiosyncratic requirements and made idiosyncratic responses to our request. Dealing with our share of the bureaucracy occupied the best part of 12 months and probably caused the loss of a medium sized Amazonian rainforest. Thus, we feel that this mechanism is an even greater hurdle than that of confidentiality.

Along with other physicians and patients, we believe that there is much information available on the way we manage many conditions if only this information could be more easily collated. The information provided by registries will increase knowledge and ultimately benefit patients. However, the issue of informed consent and the bureaucracy surrounding multicentre ethical approval needs urgent review.

James I Morrow consultant neurologist Department of Neurology, Royal Victoria Hospital, Belfast BT12 6BA 1 Brown P. Cancer registries fear imminent collapse. BMJ
2000;321:849. (7 October.)

\section{GMC is greater threat to research than} the act

EditoR-Like Strobl et al the North Staffordshire Local Research Ethics Committee has been seriously considering data protection issues while not wishing to impede research unnecessarily. ${ }^{1}$ We were concerned about the implications of the Data Protection Act. We advised researchers to consider its implications, sought advice from the data protection commissioner (emailed March 2000, response awaited), and as a last resort actually read the act. This is not a task to be undertaken lightly: the language is convoluted and arcane. None the less, section 33 of part IV of the act exempts research from most of the provisions of the act; further processing of data for purposes for which it was not originally collected (section 33 (2)) and publishing it is allowed provided the data has been anonymised (section 33 (4)(b)). The transfer of data outside the European Union, however, is prohibited (data protection principle 8) unless adequate data protection has been ensured by the country outside the union. This could present difficulties for international multicentre collaborations involving countries outside the European Union. Section 30 (1) allows the secretary of state to order that health information be exempted from the provisions of the act.

The General Medical Council's view that consent has to be obtained from participants to allow data that is already on a registry to be processed is a greater threat to epidemiological research than the Data Protection Act. $^{3}$ We may end up in the ridiculous situation in which non-medical scientists are able to do epidemiological work but registered doctors are not. There has to be a considered approach to the need for explicit consent; this approach wil depend on the degree to which records have been anonymised and the degree to which data processing has separated data from individuals. If the GMC's current position is followed to absurdity the Cochrane collaborators would have to get written consent from all participants before performing a meta-analysis.

In general, the provisions of the Data Protection Act are sensible, and researchers would do well to comply with them or be able to justify any failure to do so. Although research is exempt from some important provisions, consent is the cornerstone of ethical research and the good intentions of researchers and the inconvenience of obtaining consent will not be sufficient to explain to patients or research ethics committees the unauthorised processing of personal data.

\section{Simon J Ellis chairman}

North Staffordshire Local Research Ethics

Committee, North Staffordshire Health,

Staffordshire ST4 4LX

1 Strobl J, Cave E, Walley T. Data protection legislation: interpretation and barriers to research. BMJ interpretation and banier

2 Data Protection Act 1998. www.hmso.gov.uk/acts acts 1998/19980029.htm (accessed 8 February 2000). 3 Brown P. Cancer registries fear imminent collapse. BMJ 2000;321:849. (7 October.)

\section{New Zealand model of consent offers solution}

EDITOR-Strobl et al raise important issues about interpreting data protection legislation and its effects on research. ${ }^{1}$ These issues are familiar to researchers in New Zealand.

We have used computerised patient data for research since 1989 when the Royal New
Zealand College of General Practitioners' Dunedin Research Unit established its computer research network. ${ }^{2}$ Before the network conducted any research, the proposal was reviewed and approved by the local ethics committee. Subsequently, each proposed project has been subjected to review by the committee. The data contained on the network are anonymous: no names, addresses, or telephone numbers are ever seen by researchers. Later in the network's development, the unique alpha-numeric code used by the New Zealand public health system was attached to many files. Through a complicated process it was initially possible to identify individual patients using this code. When this was recognised, a further step was added to ensure that researchers received only encrypted identifiers. The de-encryption program is held in a central government agency and the research data are held in a university.

But where does this leave the patient's consent? Patients are informed by notices in the offices of practices affiliated with the research network that information from their consultation, investigation, or referral may be used for research once it has been stripped of identifying data. Patients are assumed to have given consent if they continue to be seen in practices affiliated with the network. So effective are the anonymisation processes that individual patients cannot be identified, even to withdraw their data. Data from whole practices can be excluded from research projects but data from individual patients cannot.

This is not a perfect system. It requires patients to act in accordance with the social responsibility they incur when they use public health systems: that is, to accept responsibility to contribute to research that advances medical knowledge. It requires researchers to act responsibly in the public interest rather than promoting the commercial interests of health related industries. It requires ethics committees to have a breadth of understanding of issues in medical research that is difficult to achieve when there is short term committee membership and high turnover. It requires everyone to question constantly what they are doing and why. But it has worked in New Zealand for more than a decade. This model may be effective in other countries.

Susan Dovey analyst

Robert Graham Center for Policy Studies in Family Practice and Primary Care, American Academy of Family Physicians, 2023 Massachusetts Ave NW, Washington, DC 20036, USA

Sdovey@aafp.org

Murray Tilyard professor of general practice Dunedin School of Medicine, University of Otago, PO Box 913, Dunedin, New Zealand

Mtilyard@gp.otago.ac.nz

1 Strobl J, Cave E, Walley T. Data protection legislation: interpretation and barriers to research. $B M J$ 2000;321:890-2. (7 October.)

2 Dovey SM, Tilvard MW. The computer research network of the Royal New Zealand College of General Practitioners: an approach to general practice research in New Zealand. Br J Gen Pract 1996; 46: 749-52. 


\section{Safeguards for research using large scale DNA collections}

\section{Study will not be started before suitable arrangements are in place}

EDITOR-As chairman of the expert planning group set up by the Medical Research Council and Wellcome Trust, I can reassure readers of the article by Kaye and Martin that all the issues they raise about the proposed population study in the United Kingdom involving genetic information have been fully recognised. ${ }^{1}$ The study will not and cannot be started until arrangements acceptable to all concerned are in place. These arrangements are currently being actively developed and entail consultation with lay and professional advisers.

The two main reasons behind the high degree of public concern and debate about the study in Iceland were the initial proposal for an "opt out" approach to consent for collection of some of the data and the decision to license the databases exclusively to a commercial company. Neither of these has ever been considered as a possibility in the British study. Consent to take part will be on an "opt in" basis only after full verbal and written explanations and guarantees on confidentiality. The availability of fully anonymised material to others in order to pursue the full scientific and therapeutic potential of the study will be tightly controlled.

The study will be overseen and regulated by a publicly accountable and independent body responsible for reviewing all its procedures and activities. In addition, full ethical approval will of course also have to be obtained. The United Kingdom has well developed, high quality expertise in both genetics and population based research, and its diverse population and healthcare system are additional advantages. Others have emphasised the importance for future health care of deriving the full benefit from recent and future developments in genetics. ${ }^{2}$

While the appropriate regulatory procedures are being put in place we should not lose sight of the willingness of many people in this country to take part in research, including work likely to benefit others perhaps more than themselves. We must ensure that they can express this readiness through their contribution to important studies such as the one the Medical Research Council and Wellcome Trust are setting up.

Tom Meade director

Medical Research Council Epidemiology and

Medical Care Unit, Wolfson Institute of Preventive

Medicine, St Bartholomew's and the Royal London

School of Medicine and Dentistry, London

EC1M 6BQ

Susan.J.Matthews@mds.qmw.ac.uk

1 Kaye J, Martin P. Safeguards for research using large scale DNA collections. BMJ 2000;321:1146-8. (4 November.)

2 Fears R, Roberts D, Poste G. Rational or rationed medicine? The promise of genetics for improved clinical practice. $B M J$ 2000;320:933-5.
Educational initiatives are essential for success of population genetic studies

EDITOR-I was delighted to see the article by Kaye and Martin on the proposed population health and diversity study of the Medical Research Council and the Wellcome Trust. ${ }^{1}$ This proposal involves the recruitment of around 500000 patients through primary care for DNA isolation and genotyping, to be linked to their medical records and family histories. These will be correlated with the prospective collection of changes in patients' lifestyles and important health events over several years.

This project may well represent the next major advance in clinical medicine, but several matters arise from the proposal. The active participation of all the relevant professional groups and the patient population is a prerequisite for the success of the project, both to enable the successful recruitment of patients and to maintain the momentum required to sustain such a longterm study. There are important educational issues that should be addressed as a matter of urgency to enable professionals in primary care to recruit patients, to obtain their informed consent, and to answer questions that arise during the course of the study.

Current and emerging technologies will allow rapid identification of mutations causing well described single gene disorders, single nucleotide polymorphism profiling, and genomic sequencing. These powerful technologies may enable the identification of predispositions to common, multifactorial disorders and predict individuals' responses to conventional therapeutic interventions. On the basis of discussions with general practitioners and practice nurses, and the findings of a recent informal survey among general practitioners in South Wales about attitudes and knowledge of genetics (unpublished data), I think that few professionals in primary care would be confident in explaining the nature of these techniques and the importance and implications of the data that would be generated. This would seriously limit the ability of professionals in primary care to obtain informed consent and answer questions that arise over the years of the study. The long term nature of the proposals reinforces the view that education and training in genetics, and particularly in the basic science that underpins the subject, are a priority for medical, nursing, and associated professions at the basic, specialist, and continuing education stages. The success of the proposed study and future population genetic studies are dependent on this educational need being immediately and effectively addressed.

Ian Hopkinson honorary consultant in primary care genetic medicine

Clinical and Molecular Genetics Unit, Institute of Child Health, London WC1N 1EH

i.hopkinson@ich.ucl.ac.uk

1 Kaye J, Martin P. Safeguards for research using large-scale DNA collections. BMJ 2000;321:1146-8. (4 November.)

\section{Mortality in joggers}

\section{Healthy jogger effect might explain differences in mortality}

EDITOR-In their cohort study of mortality in Danish men, Schnohr et al compared the mortality in 96 men who reported that they were joggers at two examinations in 1976-8 and 1981-3 with that in 4562 men who were non-joggers at both examinations. ${ }^{1}$ The authors followed up the cohort from 1976-8 to 1998 and found that the joggers' relative risk of death was 0.39 (95\% confidence interval 0.19 to 0.73 ).

The participants rather than the authors defined jogging. The paper does not include information on how or how much the men exercised at the time of the examinations or in between and after the examinations. It is not clear whether the men agreed on a common definition of jogging.

At the time of the two examinations, in 1976-8 and 1981-3, $217(4.7 \%)$ and 202 $(4.3 \%)$ respectively of the 4658 men, aged 20-79, reported that they were joggers. These numbers are surprisingly low. According to a study carried out in 1994 by the Danish National Institute for Public Health, $59.5 \%$ of men aged $\geqslant 16$ exercised or considered themselves to be physically active. Even among men aged $\geqslant 67,55.4 \%$ exercised or considered themselves to be physically active. $^{2}$

No data on mortality are presented in the paper. Because of the small number of joggers the relative risk of death is presumably sensitive to small differences in mortality even though the difference is significant

The authors point out that their study is observational and that it controls for age but not for differences in lifestyle. A healthy jogger effect rather than jogging in itself may explain the difference in mortality.

Hans Okkels Birk health economist SYHOB@RA.DK

Lars Onsberg Henriksen chief medical officer Department of Hospitals, Roskilde County, Postboks 170, DK-4000 Roskilde, Denmark

1 Schnohr P, Parner J, Lange P. Mortality in joggers: population based study of 4658 men. BMJ 2000;321:602-3. (9 September.)

2 Danish Institute for Clinical Epidemiology. Danish health and morbidity survey 1994. Copenhagen: DICE, 1998. (www.dike.dk/gammel/html/udgivel/engsusy/tabel/ index.htm (table 8); accessed 16 Jan 2001.)

Benefits are seen in previously sedentary individuals who start exercising regularly

EDITOR-The Copenhagen city heart study confirms the association between regular exercise and a reduced risk of premature death from certain illnesses. ${ }^{12}$ But the observed reduction in the risk of death from all causes only in those men who reported jogging at both of two examinations carried out five years apart conflicts with results reported elsewhere. ${ }^{34}$ We believe that this arises from pooling the results of two patterns of behaviour.

To combine the results from men who went from being active to inactive with those 
from men who went from being inactive to active (jogging at one examination) implies that the direction of change between active and inactive is immaterial and that the health state between those behaving in these different ways does not differ. This is unlikely. Stopping regular exercise may indicate declining health and an increased risk of death, whereas starting an exercise habit may be a sign of increased wellbeing and fitness. Evidence from both the United States and Britain supports this view. ${ }^{3}$

Observing changes in activity levels at three time points between 1962 and 1977, Paffenbarger et al reported that the relative risk of death from all causes in participants who at the first time point were engaged in moderately vigorous sports activity but who stopped exercising was slightly higher (1.15 (95\% confidence interval 0.73 to 1.71 )) than that in those who reported no exercise at all (1.0). ${ }^{3}$ Those who changed in the opposite direction, from being inactive to being active, had a relative risk similar to that of those who maintained a continuous exercise habit throughout the study period ( 0.77 and 0.71 respectively).

A similar pattern of health benefit in the direction from inactive to active was also found in the British regional heart study. ${ }^{4}$ This study reported that, relative to the risk in those who remained inactive, the fully adjusted risk of death from all causes in those who changed from an inactive lifestyle to participating in occasional light exercise was 0.55 (0.36 to 0.84$)$, which was slightly lower than that for continuous exercisers (0.58).

This study suggests that the benefits of a reduced risk of premature death from all causes in those previously sedentary individuals who start exercising regularly are probably as large as those in continuous exercisers; they are unlikely to be the same as those in previous exercisers who gave up exercise.

P Coleman research associate

P.Coleman@Sheffield.ac.uk

J Nicholl director

Medical Care Research Unit, School for Health and Related Research, University of Sheffield, Sheffield S1 4DA

1 Schnohr P, Parner J, Lange P. Mortality in joggers: population based study of 4658 men. BMJ 2000;321:602-3. (9 tion based stud

2 Fentem PH. Benefits of exercise in health and disease. $B M$ J 1994;308:1291-5.

3 Paffenbarger Jr RS, Hyde RT, Wing AL, Lee IM, Jung DL, Kampert JB. The association of changes in physical activity level and other lifestyle characteristics with mortality level and other lifestyle characteristics with

among men. N Engl J Med 1993;328:538-45.
4 Wannamethee SG, Shaper AG, Walker M. Changes in Wannamethee SG, Shaper AG, Walker M. Changes in
physical activity, mortality, and incidence of coronary heart disease in older men. Lancet 1998;351:1603-8.

\section{Authors' reply}

Editor-In 1976, when the Copenhagen city heart study was started, there was still some concern over whether jogging might be harmful to health. No other study had investigated this question, and we decided to ask each participant "Are you a jogger?," without further quantification of jogging. The percentage of male joggers aged 20-79 was $4.7 \%$ in the first examination (1976-8) and had increased to $8.3 \%$ in 1991-4. In

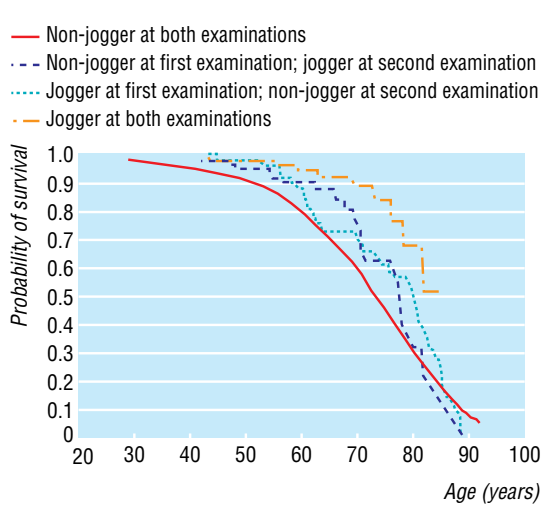

Estimated age specific survival function, using Kaplan-Meier estimator with left truncation and right censoring for four groups of joggers

addition to jogging status, information on physical activity during work and leisure time was collected, both classified into four levels. Our findings agreed with the physical activity reported in the Danish health and morbidity survey 1994.

Follow up is based on the Danish national population register, and data on mortality are therefore available for nearly all participants. Because our paper was published as a short report, with only one table or figure, however, we were unable to present age specific mortality in addition to the table. As the figure indicates here, the crude survival function for the four groups of joggers shows a remarkably clear pattern over age. The positive effect of jogging is thus unlikely to be an artefact resulting from small sample sizes.

The purpose of conducting the Cox regression analysis was to separate the effect of jogging from the effect of potential confounding variables. One should always be concerned about a possible healthy jogger effect as a partial explanation of the difference in mortality. Previous studies have shown that among its beneficial effects physical exercise (including jogging) reduces blood pressure, being overweight, and the risk of non-insulin dependent diabetes mellitus; raises high density lipoprotein cholesterol concentrations; and decreases platelet aggregation.

Peter Schnohr chief cardiologist

peterschnohr@dadlnet.dk

Jan Parner statistician

Peter Lange chief physician

Copenhagen City Heart Study, Bispebjerg

University Hospital, DK-2400 Copenhagen NV, Denmark

\section{Accuracy of ATLS guidelines for predicting systolic blood pressure}

\section{Authors' core assertion was wrong}

EDITOR-I commend the BMJ for allowing access to the editorial decision making process via the $B M J$ s website. It gives a fair meas- ure of explanation why a paper was published.

On reading the peer reviews for Deakin and Low's paper on advanced trauma life support guidelines for predicting systolic blood pressure it is evident that the referee and statistician have accepted without criticism the authors' core assertion. ${ }^{1}$ This is that the advanced trauma life support course teaches that if only the patient's carotid pulse is palpable then the systolic blood pressure is $60-70 \mathrm{~mm} \mathrm{Hg}$; if both the carotid and femoral pulses are palpable then the systolic blood pressure is $70-80 \mathrm{~mm} \mathrm{Hg}$; and if the radial pulse is also palpable then the systolic blood pressure is $>80 \mathrm{~mm} \mathrm{Hg}$.

Unfortunately, this is entirely wrong and constitutes no part of the current course or manual. ${ }^{2}$ The authors cite a guideline from $1985,{ }^{3}$ but the manual is currently in its sixth edition, with a further update due for publication this year, 2001.

One redeeming feature of the paper is that it shows (albeit at lower intra-arterial systolic pressures) an observable relation between the palpability of pulses and systolic blood pressure. But the design of the paper is open to question. Why were only 20 patients included (especially over three years)? What conditions did they have? If they had arterial lines inserted I hope that they had already received initial resuscitation. Some were undergoing operation-did they have anaesthesia? What was the status of the observer?

If we are all planning to keep our fingers on the pulses then we really must stay up to date and reaccredited.

Ian S Russell staff grade

Department of Accident and Emergency, Hartlepool General Hospital, Hartlepool TS24 9AH

iona.macleod@nth.northy.nhs.uk

1 Deakin CD, Low JL. Accuracy of the advanced trauma life support guidelines for predicting systolic blood pressure using carotid, femoral, and radial pulses: observational study. BMJ 2000;321:673-4. (16 September.)

2 American College of Surgeons. Advanced trauma life support for doctors. 6th ed Chicago: ACS, 1997.

Collicott PE Adtered trauma life support course for Collicot Pe. Advanced trauma life support course for

\section{No one relies on pulse checks alone for} subsequent clinical decision making

EDITOR-Deakin and Low have shown that if you follow the principles of advanced trauma life support you tend to overestimate the patient's blood pressure, which leads to under-resuscitation. ${ }^{1}$ They used invasive methods of blood pressure recording, possibly insertion of an arterial line. In reality, overestimation leads to "secondary survey" anyway (assuming that airway and breathing were normal); checking blood pressure is part of that. Any low blood pressure will then be picked up, and resuscitation will be started accordingly.

I have worked in different accident and emergency and trauma departments, and I have never come across anyone who relied on pulse checks alone in subsequent clinical decision making. This is because we already know that feeling a pulse has never correlated well with the blood pressure. We 
also know that the advanced trauma life support guidelines teach us very basic principles of resuscitation of trauma victims and that often we have to use our brain to evaluate further, investigate, and treat a sick patient.

I was disappointed that the authors did not compare a standard method of checking blood pressure (cuff and sphygmomanometer) with the invasive monitoring. I am sure that, if they had done, it would have given a different value. What do we do then? We cannot put an arterial line in every patient to monitor blood pressure.

Zak Baig country general practitione Minlaton Accident and Emergency Department, Minlaton, South Australia, Australia azakbaig@excite.com

1 Deakin CD, Low JL. Accuracy of the advanced trauma life support guidelines for predicting systolic blood pressure using carotid, femoral, and radial pulses: observational study. BMJ 2000;321:673-4. (16 September.)

\section{Earlier dogma seems to have been dropped now}

EDITOR-Deakin and Low tested the relation between palpable pulses and systolic blood pressure. ${ }^{1}$ We both remember being assured of this relation as students (in the days before evidence based medicine); the authors' paper questions this medical school dogma.

Advanced trauma life support is often accused of didacticism on many fronts, but we do not think that it is guilty on this occasion. We are both instructors in advanced trauma life support and have been involved at provider level since 1991. We have no recollection of this being taught as core course knowledge. We note that the offending guideline was published in 1985 and assume that it has since been dropped.

Advanced trauma life support teaches the need for rapid discovery and aggressive treatment of initial, recurrent, or persistent hypovolaemia. The finding of an absent pulse at any site, other than for local reasons, should be presumed to signify appreciable hypovolaemia. The paper supports this.

Gareth Quin consultant in accident and emergency medicine

gareth.quin@gwent.wales.nhs.uk

Gerard McCarthy consultant in accident and emergency medicine

Royal Gwent Hospital, Newport, Gwent NP9 2UB

1 Deakin CD, Low JL. Accuracy of the advanced trauma life support guidelines for predicting systolic blood pressure using carotid, femoral, and radial pulses: observational study. BMJ 2000;321:673-4. (16 September.)

\section{Author's reply}

EDITOR-The advanced trauma life support course introduced the relation between palpable pulses and blood pressure in its first edition in 1985. I agree that the paper should have clarified that the course has now stopped teaching this relation. In a short report, however, there was not enough space to discuss the evolution of the guidelines.

The reference in our paper clearly refers to the 1985 guidelines. By quoting a different reference, Russell is wrong in stating that our core assertion is incorrect. The original advanced trauma life support guidelines have been disseminated widely and continue to be taught and cited..$^{1-3}$ These unvalidated guidelines remain an often used method of quickly assessing hypotensive patients, and early advanced trauma life support teaching (and instructors) must take responsibility for their international dissemination and use.

Russell criticises the design of the paper in that only 20 patients were collected over three years. I accept that this was a small study, but it nevertheless generates data that cast doubt on the relation between pulses and blood pressure. Recruitment was limited by the number of hypotensive trauma patients seen at this hospital each year. Russell is correct in assuming that the patients received initial resuscitation, and it is for this reason that the number was limited. Are we being criticised for adequate resuscitation that has prevented hypotension in most patients? Collecting data over three years is hardly a cause for criticism.

Russell questions the 29 data points from 20 patients. We stated in the paper that "Not all pulses were palpable when a reading was taken because of impaired patient access." The raw data were submitted to the $B M J$, which declined to publish them.

Baig states he has never come across anyone who relied on pulse checks alone. I have worked in several trauma systems in the United Kingdom, particularly in the prehospital arena, where quick assessment of palpable pulses is used as an initial assessment of blood pressure and management decisions are made on the basis of pulses alone. Baig is also incorrect in stating that "we already know that feeling a pulse has never correlated well with the blood pressure." We do not.

Baig is disappointed that the study did not compare invasive and non-invasive (cuff) measurements. This was not our aim. As stated in the paper, non-invasive blood pressure measurement in hypotensive patients is inaccurate, and we deliberately avoided this measurement technique. Blood pressure was changing rapidly in many of the patients, and non-invasive pressure measurement lags behind changes in actual blood pressure. It would be unethical to wait while non-invasive pressure was measured before treating hypotension.

Charles D Deakin consultant anaesthetist Shackleton Department of Anaesthetics, Southampton General Hospital NHS Trust, Southampton SO16 6YD

cddeakin@hotmail.com

1 Pre-Hospital Trauma Life Support Committee, National association of Emergency Medical Technicians in cooperation with Committee on Trauma, American College of Surgeons. Prehospital trauma life support-instructors'manual. 3rd ed. St Louis, MO: Mosby, 1995.

2 Dalton AL, Limmer D, Mistovich JJ. Advanced medical life support. New Jersey: Prentice Hall, 1999.

3 Eaton CJ. Essentials of immediate medical care. Edinburgh: Churchill Livingstone, 1999

\section{Severity of overdose after restriction of paracetamol availability}

\section{Study's results conflict with those of other papers}

EDITOR-Robinson et al report a reduction in the amount of paracetamol ingested in overdose since the introduction of reduced pack sizes and blister packing of over the counter paracetamol in September 1998. They found no change, however, in the incidence of hepatotoxicity. Their results contrast with those of other studies, which have shown a $21 \%$ reduction in episodes of hepatotoxicity and a $64 \%$ reduction in the development of severe hepatotoxicity. ${ }^{23}$

As they have stated, hepatic failure is rare if $<12 \mathrm{~g}$ of paracetamol is ingested. ${ }^{4}$ But the median dose ingested in their study did not reach this level. It is thus unsurprising that the study included only five cases of hepatotoxicity; given this low number, it seems imprudent to claim that no change in incidence has occurred.

In addition, the paracetamol concentrations quoted in the paper are low, considering that concentrations $>200 \mathrm{mg} / \mathrm{l}$ four hours after ingestion and $>130 \mathrm{mg} / \mathrm{l}$ six hours after ingestion are used to guide the appropriate use of acetylcysteine treatment. Despite the low concentrations quoted, acetylcysteine was given to $25 \%$ and $31 \%$ of patients. This does not seem to accord with current practice recommendations.

Robinson et al conclude that the change in pack size had no effect on the incidence of severe liver failure. In our view, a stricter definition of paracetamol overdose is required if we are to make sense of the conflicting reports. Perhaps paracetamol overdose should be confined to subjects who claim to have taken an overdose and have a measurable serum concentration.

The burden of paracetamol poisoning on the NHS is high, with over 70000 episodes a year in Britain. ${ }^{5}$ It is worrying that the recent measures have not had a more dramatic effect on this serious problem. If, as Turvill et al say, ${ }^{3}$ only a $21 \%$ reduction has been achieved then further measures such as limiting paracetamol to prescription only should be considered.

C L Sheen clinical research fellow chris@memo.dundee.ac.uk

T M MacDonald professor of pharmacology and pharmacoepidemiology

Medicines Monitoring Unit, University of Dundee, Ninewells Hospital and Medical School, Dundee DD1 9SY

Competing interests: CLS is funded by an unrestricted fellowship from Pfizer to study the toxicity of over the counter non-steroidal antiinflammatory drugs and other analgesics. TMM is a member of the subcommittee on pharmacovigilance of the Committee on Safety of Medicines.

1 Robinson D, Smith AMJ, Johnston GD. Severity of overdose after restriction of paracetamol availability: retrospective study. BMJ 2000;321:926-7. (14 October.)

2 Prince MI, Thomas SHL, James OFW, Hudson M. Reduction in incidence of severe paracetamol poisoning. Lancet 2000:355:2047-8. 
3 Turvill JL, Burroughs AK, Moore KP. Change in occurrence of paracetamol overdose in UK after introduction of blister packs. Lancet 2000;355:2048-9.

4 Routledge P, Vale JA, Bateman DN, Johnston GD, Jones A, Judd A, et al. Paracetamol (acetaminophen) poisoning. BMJ 1998;317:1609-10.

5 Fagan E, Wannan G. Reducing paracetamol overdoses. BMJ 1996;313:1417-8.

\section{Restriction has not reduced admissions with self poisoning}

EDITOR-The report by Robinson et al, ${ }^{1}$ and other reports, ${ }^{23}$ suggests that restriction of sales of paracetamol has reduced the number and severity of paracetamol poisonings. This is welcome, but the effect on all cases of self poisoning has not been considered. Suspecting that selective restriction of paracetamol would result in other drugs being substituted, ${ }^{4}$ we carried out a study to look at this.

We surveyed all admissions for overdose before and after sales of paracetamol were restricted: 116 patients (group A) were admitted in the six months before paracetamol was restricted (February-August 1998) and 112 patients (group B) during February-August 1999. Altogether 52 (45\%) paracetamol poisonings occurred before the restrictions were put in place and $40(36 \%)$ after. The number of paracetamol tablets taken was known for 44 patients in group A and 35 in group B. Thirty $(68 \%)$ patients took more than 16 tablets before rationing and $18(51 \%)$ afterwards; this was reflected in the need for treatment with acetylcysteine, which fell from 16 cases to nine.

Although paracetamol overdose declined, non-paracetamol poisoning increased (from 64 to 72 cases), predominantly involving antidepressant, antipsychotic, and sedative drugs. For both sample periods the average time that each patient spent in hospital was the same (2.6 days). One death occurred from a tricyclic overdose. Although admissions with paracetamol overdose fell, the numbers of cases and bed days needed for care did not alter. Drug selection in self poisoning is usually dictated by what is immediately available, whether obtained over the counter or by medical prescription. ${ }^{5}$

Our patients used over 50 different prescription only drugs for overdose, which had been obtained previously for therapeutic purposes. Our results suggest that patients are now switching to alternative agents, often as part of a multidrug cocktail, with equivalent risk because of individual toxicity and interaction. There may be less demand on liver units, ${ }^{2}$ but the unwanted workload for general physicians is the same. More restraint in drug prescription may have a greater effect on the incidence and morbidity of, and mortality from, self poisoning than this simplistic restriction of paracetamol has had.

Mohan R Thomas staff grade physician

Nigel I Jowett consultant physician nigel.jowett@pdt.tr.wales.nhs.uk

Department of Medicine, Withybush General

Hospital, Pembrokeshire SA61 2PZ

Competing interests: None declared.
1 Robinson D, Smith AMJ, Johnston GD. Severity of overdose after restriction of paracetamol availability: retrospective study. BMJ 2000;321:926-7. (14 October.)

2 Prince MI, Thomas SH,James OFW, Hudson M. Reduction in incidence of severe paracetamol poisoning. Lance 2000;355:2047-8.

3 Turvill JI, Burroughs AK, Moore KP. Change in occurrence of paracetamol overdose in UK after introduction of blister packs. Lancet 2000;355:2048-9.

4 Jowett NI. Limitation of over the counter sales of paracetamol. BMJ 1998;317:1657.

5 Hawton K, Ware C, Mistry H, Hewitt J, Kingsbury S, Roberts D, et al. Why patients choose paracetamol for self Roisoning $1995 \cdot 310: 164$

\section{Why hasn't strategy for minimising} paracetamol poisoning been enacted?

EDITOR-It has been well known for nearly 20 years that adding methionine or acetylcysteine to each paracetamol (acetominophen) tablet provides the liver with sufficient reserve of the sulphydryl group to conjugate the toxic paracetamol metabolites. So why haven't our regulators mandated such?

If paracetamol were a dietary supplement it would have been put into the "most toxic substance on earth" category and banned long ago. Drug interactions with $\mathrm{St}$ John's wort (most of which were hypothetical) were acted on with great haste by regulators around the world, despite no deaths ever having been associated with use of St John's wort. Here we have a drug that is available from petrol stations and corner shops and has been killing thousands of people around the world for years, and our regulators turn a blind eye-even when there is a simple solution.

Why the double standards and the hypocrisy?

Ron Law lecturer in management

Faculty of Business, Auckland University of Technology, Private Bag 92006, Auckland 1, New Zealand

juderon@ihug.co.nz

Competing interests: RL is a member of the working group advising the New Zealand Ministry of Health on mandatory reporting of medical error policy. He is also executive director of the National Nutritional Foods Association and is motivated by injustice.

\section{Guidelines for prevention of falls in people aged over 65}

Guidelines should state that assessment of vision is important

EDITOR-A fall in an older person can have severe personal as well as healthcare implications. Feder et al have given important guidelines for the prevention of falls in people aged over $65 .^{1}$ Their aim was to translate trial evidence into recommendations to reduce the rate of falls in people aged over 65 .

The methods used to gather information did not seem to include any references to the patients' visual function. There have been several reports linking poor visual function with an increased risk of falls or fractures related to falls..$^{2-4}$ A recent study by Ivers et al shows that decreased visual function is a risk factor for hip fractures.
It would seem logical that people who do not see well are more likely to fall than those who do see well. It is unfortunate, then, that the guidelines given do not contain any references to improving visual function. Poor vision is quite common in elderly people. The causes are varied and include problems related to spectacles (not wearing them, incorrect prescription, scratched lenses, inability to afford them, inappropriate lenses), cataracts, glaucoma, age related macular degeneration, diabetic retinopathy, and other vascular abnormalities.

We believe that regular visual assessments should be included in the guidelines aimed at the prevention of falls. An ophthalmologist should assess patients with potentially treatable eye disease. Perhaps we should more often consider the risk of falling when we assess our patients with cataracts and other eye disease. Certainly, patients with poor vision from untreatable causes should be provided with low vision aids as appropriate. These patients may also be the ones most likely to benefit from other interventions, as set out by Feder et al.

R R Seemongal-Dass specialist registrar

T E James consultant

C. E Atherley specialist registrar

Department of Ophthalmology, St James's

University Hospital, Leeds LS9 7TF

robindass@hotmail.com

Competing interests: None declared.

1 Feder G, Cryer C, Donovan S, Carter Y. Guidelines for the prevention of falls in people over 65. BMJ 2000;321:1007 11. (21 October.)

2 Klein BE, Klein R, Lee KE, Cruikshanks KJ. Performancebased and self-assessed measures of visual function related to the history of falls, hip fractures, and mction it the the heaver Dam eye study. Ophthasured gait time. The B

Treable and unteathe risk factors for hip fracture. Bone 1996;18(suppl 3):165-7S

hip fracture. Bone 1996;18(suppl 3):165-7S. Felson DT, Anderson JJ, Hannan MT, Wilson PW, Kiel DP.
Impaired vision and hip fracture. The Framingham study. Impaired vision and hip fracture.

JAm Geriatr Soc 1989;37:495-500.

5 Ivers RQ, Norton R, Cumming RG, Butler M, Campbell AJ. Visual impairment and risk of hip fracture. Am J Epidemiol 2000;152:633-9.

\section{Health improvement plans must incorporate falls and osteoporosis strategies}

Editor-Feder et al address the important issue of minimising the injuries that result from falls by elderly people. ${ }^{1}$ Falls are the most frequent cause of morbidity and mortality related to injury in elderly people and as such represent a major public health problem. Injuries related to falls will pose even greater challenges to the health service with an ageing population.

Hip fracture is one of the most costly and debilitating outcomes resulting from a fall but occurs in only $1 \%$ of falls. ${ }^{2}$ It is well known, however, that over $90 \%$ of hip fractures are associated with a fall. Clearly, falling is only part of the problem. Fracture is determined not only by the propensity to fall but also by the underlying fragility of the bone. Experts estimate that in people aged over 75 over $90 \%$ of hip fractures are attributable to fragile bones due to osteoporosis ${ }^{3}$; there is simply too little bone in the bone.

In the NHS at a local level, health improvement plans must integrate falls and 


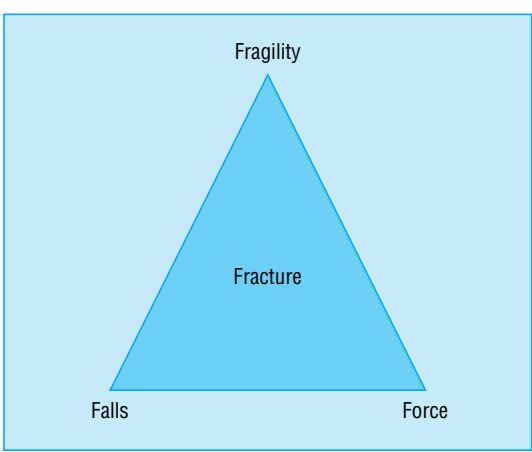

Fracture prevention triangle

osteoporosis strategies. Without the integration of these local initiatives elderly fallers will most probably receive an assessment and intervention after falling but will not be assessed or treated to reduce the risk of fracture should a further fall occur. This was shown recently in a study by Kamel et al, where only $5 \%$ of women admitted to a community hospital in the United States over two years left with new drug treatment prescribed to prevent a further fracture. ${ }^{4}$ Furthermore, patients with osteoporosis may not have their risk of falling investigated and receive only bone strengthening treatment.

Strategies to reduce fractures, especially of the hip, need to address both falling and bone strength. A review of more than 300 publications related to falls, and interviews with more than 50 healthcare professionals, led to the development of a simple fracture prevention model, which clearly highlights three intervention points for fracture (figure). ${ }^{5}$

Interventions that aim to prevent fractures should aim at reducing the risk of falling, strengthening people's bones, and reducing the force of impact of a fall on people's bones. It is to be hoped that the national service framework for older people's services will pick up where Feder et al's work leaves off, by making clear the need to address both osteoporosis and falls in local strategies.

Mark Chakravarty head of government affairs Procter and Gamble Pharmaceuticals, Staines, Middlesex TW18 3AZ

chakravarty.m@pg.com

Anna Sörman head of government and NHS policy Aventis Pharmaceuticals, West Malling, Kent ME19 4AH

Competing interests: MC is employed by and has shares in Procter and Gamble. AS is employed by and has shares in Aventis Pharma. Procter and Gamble and Aventis Pharma form the Alliance for Better Bone Health and manufacture and market risedronate sodium (Actonel) for postmenopausal osteoporosis.

1 Feder G, Cryer C, Donovan S, Carter Y. Guidelines for the prevention of falls in people over 65. BMJ 2000;321:1007 11. (21 October.)

2 Tinnetti ME, Speechley M, Ginter SF. Risk factors for falls among elderly persons living in the community. $N$ Engl J Med 1988;319:1701-7.

3 Phillips S, Fox N, Jacobs J, Wright WE. The direct medical costs of osteoporosis for American women aged 45 and older, 1986. Bone 1988;9:271-9.

4 Kamel HK, Hussain MS, Tariq S. Failure to diagnose and treat osteoporosis in elderly patients hospitalized with hip fracture. Am J Med 2000;109:326-8.

5 National Institutes of Health Osteoporosis and Related Bone Diseases National Resource Center. NIH ORBDBone Diseases National Resource Center. NIH ORBDNRC news: falls and fracture prevention.. Vol 2, No 1 Washington, DC: NIH ORBD-NRC, 1999. Available at
www.osteo.org/newsvol2nol.html (accessed 22 Nov 2000).

\section{Unicef is crucial in promoting} and supporting breast feeding

EdITOR-The report from the NHS Centre for Reviews and Dissemination highlights many of the reasons why the work of the Unicef UK baby friendly initiative is a crucial component of any strategy to promote and support breast feeding. ${ }^{1}$

Although breastfeeding rates in the United Kingdom have remained static since $1980,{ }^{2}$ a survey of 21 baby friendly hospitals has found an increase of more than $10 \%$ in breastfeeding initiation. The percentage of babies who are breast fed rose from $60 \%$ two years before the units received their baby friendly award to $70.6 \%$ a year after their accreditation (table). Some of the largest increases were in hospitals serving inner city or deprived areas, which traditionally have low rates. For example, breastfeeding initiation at the Ulster Hospital in Belfast has increased from $29 \%$ in 1995 to $55 \%$ now. Some hospitals in areas with traditionally strong breastfeeding rates have also shown increases with the Royal Surrey Hospital, Guildford, showing a rise from 74\% in 1995 to $86 \%$ today.

Compounding the problem of the low uptake of breastfeeding is the rapid decline in prevalence. Each year, 75000 mothers stop breast feeding in the first postnatal week, but only $1 \%$ say that this is how long they had intended to breast feed for. The reasons most give for stopping relate to problems that could be avoided or solved if they were better supported. ${ }^{3}$ The principle behind the baby friendly initiative is that best practice standards should be adopted so that health professionals are able to support mothers in their chosen feeding method. Healthcare facilities which implement best practice--the 10 steps to successful breastfeeding for the maternity services $^{4}$ or the seven point plan for the protection, promotion, and support of breast feeding in community healthcare settings ${ }^{5}-$ can be assessed and accredited as baby friendly. The standards combine the foundations of good practice (policy, training, information) with changes to practice (skin to skin contact, rooming in, exclusive breast feeding) and good cooperation between the different parts of the health service and the voluntary sector.

Thirty one maternity units in the United Kingdom have a full baby friendly award, and another 68 have a certificate of commitment, which rewards the development of a detailed action plan. We hope that the latest

Birth rates and incidence of breast feeding in 21 hospitals according to timing of accreditation by Unicef UK baby friendly initiative

\begin{tabular}{lcc} 
Accreditation & No of births & $\begin{array}{c}\text { No }(\%) \text { of babies } \\
\text { breast fed }\end{array}$ \\
\hline Two years before & 34538 & $20719(60.0)$ \\
\hline One year before & 34122 & $21563(63.2)$ \\
\hline During & 33861 & $22365(66.1)$ \\
\hline One year after & 22552 & $15930(70.6)$ \\
\hline
\end{tabular}

*Includes figures for part of year for hospitals accredited during 1999. report will accelerate progress among the remaining units.

Andrew Radford programme director

Unicef UK Baby Friendly Initiative, London WC2H 9TA

1 Kmietowicz Z. Breastfeeding programmes "should be Kmietowicz Z. Breastfeeding programmes
targeted." BMI 2000;321:467. (19-26 August.)

targeted." BMJ 2000;321:467. (19-26 August.)
Foster K, Lader D, Cheesbrough S. Infant feeding 1995. 2 Foster K, Lader D, Cheesbrough
London: Stationery Office, 1997.

3 Unicef UK Baby Friendly Initiative. Baby friendly hospitals show strong increase in breastfeeding rates. Baby Friendly News No 6, July 2000

4 WHO/Unicef. Protecting, promoting and supporting breastfeeding: the special role of maternity services. A Joint WHO/Unicef Statement. Geneva:WHO, 1989.

5 Unicef UK Baby Friendly Initiative. The baby friendly initiative in the community -an implementation guide. London: Unicef UK Baby Friendly Initiative, 1999.

\section{Evidence and belief in attention deficit hyperactivity disorder}

\section{Narrow focus of editorial was disappointing}

EdiToR-The editorial by Zwi et al suggested that current practice in attention deficit hyperactivity disorder is largely based on belief with little good evidence available. ${ }^{1}$ Its narrow focus on inadequate methods in studies was, however, disappointing, barely touching the surface of the controversies surrounding attention deficit hyperactivity disorder and the prescription of stimulants. The disorder construct raises more questions than it answers. For example, where is the cut-off point between normal behaviour and attention deficit hyperactivity disorder? Who defines this, and why? (What does the $>30$-fold variance in prevalence rates in epidemiology studies mean?) Why is this diagnosis predominantly given to boys? (Is Western culture more concerned with externalised behaviour seen in boys than internalised behaviour of girls?) Why the very high rates of comorbidity with other psychiatric disorders? (Is attention deficit hyperactivity disorder a research generated idea that has little relation to the complexity commonly found in clinical practice?) Is the disorder being diagnosed more commonly because of a real increase or because of a change in the way certain behaviours are interpreted? (If there is a real increase in the disorder, what is the environmental cause?)

The wider questions about the prescription of stimulants were not considered in this article. For example, does the prescription create a medical script for understanding life's problems that could persist in a dysfunctional way in later life (a pill to solve problems)? Is it possible that, as well as sometimes alleviating stigma, we as doctors may contribute to stigma and intolerance by labelling and treating with drugs? Are we being duped by a powerful multimillion dollar drug industry into miracle cures? It is also incorrect, as Zwi et al stated, that there is no evidence of long term harmful consequences. Evidence (however poor the studies) has been put forward that long term prescription of stimulants could result in poor growth, cognitive deterioration, tics, 
obsessionality, flat affect, moodiness, tolerance, and dependence.

Parents making the difficult decision whether to accept stimulants for their child should be given the full information about the controversies to allow them to make an informed decision. However, the medical literature should also broaden the debate from the narrow tunnel vision of pure medical models to develop a dialogue with other disciplines and explore concepts such as attention deficit hyperactivity disorder from a different perspective.

Sami Timimi consultant child and adolescent psychiatrist

Lincoln District Healthcare NHS Trust, Lincoln LN2 5RT

Z Zwi M, Ramchandani P, Joughin C. BMJ 2000;321:975-6. (21 October.)

\section{Reintroduction of methylphenidate in Italy needs careful monitoring}

EDITOR-In their editorial Zwi et al emphasised that informed decision on the use of stimulants for the treatment of attention deficit hyperactivity disorder must be based on studies with good methods. ${ }^{1}$ Two weeks after publication of the editorial the $B M J$ reported that the National Institute for Clinical Excellence (NICE) suggested that methylphenidate should be used as part of a comprehensive treatment programme for children with this disorder. ${ }^{2}$ In Italy methylphenidate was withdrawn from the market in 1989 by the manufacturer, and since then children with the disorder have received treatment with tricyclic antidepressants, benzodiazepines, and questionable drugs that are not evidence based. In October 2000 this situation led a group of paediatricians in primary care to lobby the national health department for the immediate reintroduction of methylphenidate. As a consequence, the drug will once again be marketed in Italy.

This outcome has been reported as a success for primary care paediatricians, also appearing as such in the email responses posted to the main Italian paediatric online discussion group (www.pediatria.it). All correspondents were enthusiastic about the forthcoming availability of methylphenidate, and none warned about the possibility of overusing this stimulant or the need to educate primary care paediatricians better on the comprehensive management of attention deficit hyperactivity disorder. This is worrying in Italy in view of the lack of knowledge about the syndrome's incidence, the lack of awareness in general practice of diagnostic criteria and therapeutic guidelines, and the documented adverse reactions that necessitate systematic monitoring.

We recently conducted a survey of the knowledge and attitudes towards attention deficit hyperactivity disorder among the 86 primary care paediatricians in Turin attending 77378 children. ${ }^{4}$ Eighteen of the 56 respondents did not know about the existence of this disorder, $34 \mathrm{did}$ not know the criteria needed for diagnosis, and only six followed up suspected cases directly. The drug most used for the disorder was niaprazine, an antihistamine commonly prescribed in Italy and a few other countries to treat children with sleep disorders.

We agree with the conclusion of Zwi et al that stimulants should be prescribed judiciously and monitored carefully. This is especially true in Italy, where primary care paediatricians so far have a limited experience in the effective management of attention deficit hyperactivity disorder. Their role in initiating prescribing for this condition also needs to be thoroughly examined in specific, applied research initiatives. ${ }^{5}$

Maurizio Bonati head

Piero Impicciatore senior research fellow

Chiara Pandolfini research fellow

Laboratory for Mother and Child Health, Istituto di Ricerche Farmacologiche Mario Negri, Via Eritrea 62, 20157 Milano, Italy

mother_child@irfmn.mnegri.it

1 Zwi M, Ramchandani P, Joughin C. Evidence and beliefs in ADHD. BMJ 2000;321:975-6. (21 October.)

Dobson R. NICE issues new guidelines on Ritalin. $B M$ 2000;321:1100. (4 November.)

3 Barkley RA, McMurrey MB, Edelbrock CS, Robbins K Side effects of methylphenidate in children with attentio deficit hyperactivity disorder; a systemic, placebocontrolled evaluation Pediatrics 1990:86:184-99.

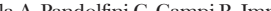
Marchini L, Puzzo F, Pirella A, Pandolfini C, Campi R, Impicciatore P, et al. Se non sta fermo solo in
ricetta. Occhio Clinico Pediatria 2000:4:12-14.

5 Thomas P. The research needs of primary care. $B M J$ 2000;321:2-3.

\section{Twins and asthma}

Difference in admission rates may be due to other factors

EDITOR-Strachan et al found an interesting difference between admissions to hospital for childhood asthma between twins and singletons. ${ }^{1}$ They conclude that there is reduced risk of asthma among twins. We found no significant difference in questionnaire based asthma diagnoses between singletons and twins aged 30-59 years among the Finnish twin cohort, but we did not give figures. ${ }^{2}$ The Finnish twin cohort is a population based sample of adult twin pairs of the same sex selected from the central population registry of Finland as pairs of individuals with the same birth date and sex, as well as the same surname and local community of birth. These selection criteria also captured some unrelated individuals The unpublished figures are based on 12024 twins and 2015 singletons. Age standardised prevalences of asthma were 2.1 (95\% confidence interval 1.6 to 2.5 ) for male twins and 2.1 (1.1 to 3.0) for male singletons. For women, prevalences were 2.1 (1.7 to 2.5$)$ and 2.5 (1.4 to 3.5) respectively. These findings are in accordance with studies among children and young adults from Finland and other Nordic countries. ${ }^{3-5}$ The reported occurrences of asthma in these twin studies correspond to those found in general populations. Although limitations arise because of interstudy differences (such as age range, definition of asthma, and study period) these studies support our findings among older adults.

The reported differences in rates of admission to hospital may also be caused by different use of medical care among twins and singletons. Mothers of twins are on average older than mothers of singletons, and they usually also have other children. They therefore have more experience with children and their diseases. It is also probable that, when one twin has been in hospital for asthma, parents do not seek help for his or her twin sibling so easily because the situation is already familiar and medication may even be available at home.

Elisa Huovinen researcher

elisa.huovinen@helsinki.fi

Department of Public Health, University of

Helsinki, FIN-00014 Helsinki, Finland

Jaakko Kaprio professor of public health

jaakko.kaprio@helsinki.fi

Department of Public Health and General Practice, University of Oulu, FIN-90014 Helsinki, Finland

1 Strachan DP, Moran SE, McInnery K, Smalls M. Reduced risk of hospital admission for childhood asthma amon Scottish tins: Scottish twins: 1 cco

2 .

Huovinen E, Kaprio J, Laitinen LA, Koskenvuo M Incidence and prevalence of asthma among adult Finnis men and women of the Finnish Twin Cohort from 1975 to 1990, and their relation to hay fever and chronic bronchitis. Chest 1999;115:928-36

3 Räsänen M, Laitinen T, Kaprio J, Koskenvuo M, Laitinen LA. Hay fever, asthma and number of older siblings-a twin study. Clin Exp Allergy 1997;27:515-8.

4 Skadhauge LR, Christensen K, Kyvik KO. Genetic and environmental influence on asthma: a population-based study of 11,688 Danish twin pairs. Eur Respir J 1999;13: $8-14$

5 Harris JR, Magnus P, Samuelsen SO, Tambs K. No evidence for effects of family environment on asthma, retrospective study of Norwegian twins. Am I Respir Crit Care Med 1997:156:43-9.

\section{Author's reply}

EDITOR-Huovinen and Kaprio present useful data suggesting that among adults there is little difference in asthma prevalence between twins and singletons. There is growing recognition that wheezing illness in early childhood (when most hospital admissions for asthma occur in the United Kingdom) may be a different spectrum of disease to asthma in adulthood. This may explain the contrasting findings of our respective studies.

The three other studies cited by Huovinen and Kaprio did not compare twins directly with singletons by using a standard method of identifying asthma, but simply commented on the results from twin series in the context of local prevalence studies, which may have used different case definitions. The strength of our study and that of Bråbäck et al is that identical methods of case ascertainment were used among twins and singletons, leading to less misleading comparisons. ${ }^{1}$

We alluded to the possibility that patterns of health service contact might have exaggerated the difference in admission rates between twins and singletons. However, the cumulative risk of admission for asthma by age 10 years among Scottish singletons born 1981-4 was only $2 \%$, so it is unlikely that prior admission of the co-twin would influence asthma management in more than a small proportion of twins.

David Strachan professor of epidemiology Department of Public Health Sciences, St George's Hospital Medical School, London SW17 0RE

1 Bråbäck L, Hedberg A. Perinatal risk factors for atopic disease in conscripts. Clin Exp Allergy 1998;28:936-42. 


\section{Eradicating Helicobacter pylori in non-ulcer dyspepsia may not be cost effective}

EDITOR-Finding that patients with dyspepsia gain modest benefits from eradication of Helicobacter pylori, Moayyedi et al conclude This conclusion should be taken with quite a bit of healthy scepticism. They say that one patient benefiting out of 15 treated with antibiotics may represent good value for money, depending on decision makers' willingness to pay for relief of dyspepsia. However, the risks associated with the antibiotic treatment are not taken into account in the economic model used.

The table summarises the results of two of the included trials, ${ }^{23}$ showing an absolute increase in withdrawal from the trial due to adverse events. Number needed to harm values are very close to the number needed to treat found by Moayyedi et al, meaning that of each 15 patients treated one could benefit but another one could experience side effects leading to withdrawal from the trial. Moreover, a message to test and eradicate $H$ pylori in all patients with non-ulcer dyspepsia could lead to a long term risk of antibiotic resistance.

Additionally, dyspepsia was "forced" into a dichotomous outcome. There may be different degrees of upper abdominal pain or discomfort, so considering dyspepsia only as "present" or "absent" oversimplifies the picture. In specifying a number needed to treat of 15 , the authors cannot say what improvement is gained by patients who responded to treatment. If 15 patients are treated and one of them benefits, how different is this one from the other 14? Data on quality of life included in the review seem to show that there are no differences between the eradication and control groups.

The studies included in this metaanalysis use quite different scales to measure dyspepsia. In the Glasgow scale, scores of $0-1$ out of 21 represent a favourable outcome ${ }^{4}$; in some Likert scales, scores of $0-1$ out of 4 to 7 points represent the same outcome. $^{23}$ The discriminative power of these scales is obviously very different, and combining results derived from using such scales may be problematic. decrease the long term use of acid suppressive treatment. More than $50 \%$ of patients with non-ulcer dyspepsia still take such treatment five years after the successful eradication.

Finally, most of the studies included in this meta-analysis come from secondary that this intervention "may be cost effective."

Eradicating $H$ pylori does not seem to care. It may be difficult to generalise these results to primary care patients who may differ in terms of adherence to treatment and severity of symptoms.

Giulio Formoso epidemiologist g.formoso@ausl.mo.it

Emilio Maestri consultant

Nicola Magrini head, Unit of Drug Evaluation and Evidence-Based Primary Care

Centre for the Evaluation of Effectiveness of Health Care, Viale Muratori 201, 41100 Modena, Italy

Maurizio Koch gastroenterologist

Lucio Capurso gastroenterologist

Department of Gastroenterology, General Hospital S Filippo Neri, Rome, Italy

Alessandro Liberati professor of biostatistics University of Modena and Reggio Emilia, Via Università 4, 41100 Modena

1 Moayyedi P, Soo S, Deeks J, Forman D, Mason J, Innes M, et al. Systematic review and economic evaluation of Helicobacter pylori eradication treatment for non-ulce dyspepsia. BMJ 2000;321:659-64. (16 September.)

2 Blum AL, Talley NJ, O'Morain C, van Zanten SV, Labenz. Stolte M, et al. Lack of effect of treating Helicobacter pylo in patients with nonulcer dyspepsia. Omeprazole plu Clarithromycin and Amoxicillin Effect One Year afte Treatment (OCAY) Study Group. $N$ Engl J Med 1998;339:1875-81.

3 Talley NJ, Vakil N, Ballard ED 2nd, Fennerty MB. Absence of benefit of eradicating Helicobacter pylori in patients with nonulcer dyspepsia. N Engl J Med 1999;341:1106-1 4 El-Omar EM, Banerjee S, Wirz A, McColl KE. The Glasgow dyspepsia severity score-a tool for the global measurement of dyspepsia. Eur J Gastroenterol Hepatol 1996;8:

5 Tan AC, Hartog GD, Mulder CJ. Eradication of Helicobacter pylori does not decrease the long-term use of acid-suppressive medication. Aliment Pharmacol The $1999 ; 13: 1519-22$

\section{Tobacco industry must not dump its high nitrosamine tobacco on poor countries}

EDITOR-In the late 1970s Hoffmann's group described the carcinogenic properties of the tobacco-specific nitrosamines including 4-(N-methyl-N-nitrosamino)-1-(3-pyridyl)-1butanone and N'-nitrosonornicotine in a series of experiments. ${ }^{1}$ These substances are formed during the curing process by a chemical reaction between nicotine and nitrate. They are present in cigarettes, chewing tobacco, and snuff. One of the substances, 4-(N-methyl-N-nitrosamino)-1(3-pyridyl)-1-butanone, is of particular interest as it is a powerful lung adenocarcinogen in animals regardless of route of administration. Adducts of $\mathrm{N}^{\prime}$-nitrosonornicotine and 4-(N-methyl-N-nitrosamino)-1-(3-pyridyl)-1butanone are seen in the lungs of humans and animals and are closely correlated with carcinogenicity. $^{2}$

Hoffmann and Hoffmann later published analyses of a single regular cigarette brand in the United States. In 1995 they showed an increase (of about half) in
4-(N-methyl-N-nitrosamino)-1-(3-pyridyl)1-butanone in the smoke during a time when the benz(a)pyrene level was stable. ${ }^{3}$ This was associated with an increase in the nitrate content of tobacco in the United States over that time and also with a fall in Federal Trade Commission measures of tar and nicotine.

The increase in 4-(N-methyl-Nnitrosamino)-1-(3-pyridyl)-1-butanone (and other tobacco-specific nitrosamines) was also associated with the significant increase in the relative and absolute risk of adenocarcinoma of the lung seen in the United States and other countries. ${ }^{3}$ It has been postulated that the increase in tobacco-specific nitrosamines (together with overinhalation due to compensatory smoking behaviour) is at least partly responsible for the increase in adenocarcinoma.

Nitrosamine levels vary widely both within brands and between countries. ${ }^{4}$ The levels of tobacco-specific nitrosamines in smoke have always been under the control of the manufacturer. In 2000, new curing technology that leads to major reductions in tobacco-specific nitrosamines was introduced in the United States. ${ }^{5}$ This development raises serious questions. Will surplus high nitrosamine tobacco be exported? If so will it go to countries, such as China, where nitrosamines are already lower than they are in the United States? Will the global companies use this technology worldwide? If not, why not?

Removing nitrosamines might well reduce the incidence of adenocarcinoma over time. Only an experiment on continuing smokers will tell, and this should be set up. Removing nitrosamines will not affect the epidemic of other cancers and diseases associated with tobacco, but there can be little excuse for not insisting that the tobacco industry uses this technology globally and does not dump its high nitrosamine tobacco on poor countries. Every national government should take note.

Nigel Gray senior research associate nigel@uicc.c

Peter Boyle director

Division of Epidemiology and Biostatistics,

European Institute of Oncology, 20141, Milan, Italy

1 Hecht SS, Chen CB, Hirota N, Ornaf RM, Tso TC, Hoffmann D. Tobacco-specific nitrosamines: formation from nicotine in vitro and during tobacco curing and carcenogenicity in strain A mice. J Natl Cancer Inst 1978;60:819-24.

2 Hecht SS. DNA adduct formation from tobacco-specific N-nitrosamines. Mutation Research 1999;424:127-42.

3 Hoffmann D, Hoffmann I. The changing cigarette, 1950-1995.J Toxicol Environ Health 1997;50:307-64

4 Gray N, Zaridse D, Robertson C, Krivosheeva L, Sigacheva $\mathrm{N}$, et al. Variation within global cigarette brands in tar, nicotine, and certain nitrosamines: analytic study. Tobacco Control 2000;9:351.

5 Fisher B. Curing the TSNA problem. Tobacco Reporter 2000

Aug:53-6.

Withdrawals owing to side effects and numbers needed to harm in two trials of Helicobacter pylori eradication (follow up of one year)

\begin{tabular}{|c|c|c|c|c|}
\hline \multirow[b]{2}{*}{ Study } & \multicolumn{2}{|c|}{ Withdrawal owing to side effects (\%) } & \multirow{2}{*}{$\begin{array}{l}\text { Increase in } \\
\text { absolute risk }\end{array}$} & \multirow[b]{2}{*}{ No needed to harm } \\
\hline & Eradication group & Control group & & \\
\hline Blum et $\mathrm{al}^{2}$ & 7 & 1 (omeprazole) & 6.0 & 17 \\
\hline Talley et $\mathrm{al}^{3}$ & 4 & 0 (placebo) & 4.0 & 25 \\
\hline
\end{tabular}

There were 348 participants in the Blum et al study and 170 in the Talley et al study.

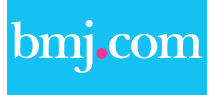

\section{Rapid responses}

Correspondence submitted electronically is available on our website 